\title{
UNA APROXIMACIÓN AL ESTATUTO LEGAL DE LAS ACLLAS Y DE LAS PROSTITUTAS EN EL INCANATO A PARTIR DE LOS COMENTARIOS REALES
}

\author{
AN APPROACH TO THE LEGAL STATUS OF ACLLAS AND PROSTITUTES \\ DURING THE INCA TIMES ACCORDING TO THE COMENTARIOS REALES
}

Rosa Carrasco Ligarda ${ }^{1}$

\section{RESUMEN}

En el presente trabajo presenta las normas que regulan la vida de las escogidas y de las prostitutas en el imperio incaico, según lo revela el Inca Garcilaso de la Vega. Todas las menciones son de la edición de los Comentarios reales de los incas [1609 1. ${ }^{a}-16162$ 2.] $^{\text {a] }}$ publicada en Lima (1985) por la Biblioteca Peruana. Los puntos que se desarrollan se contrastan, amplían o complementan con las crónicas de Francisco de Xerez [1534], Juan de Betanzos [1551*], Pedro de Cieza de León [1553], Juan de Matienzo [1567*], Pedro Pizarro [1571*], José de Acosta [1590], Blas Valera [1588?*], Miguel Cabello de Balboa [1586*], Martín de Murúa [1590*], Antonio de Herrera (1615), Guamán Poma de Ayala [1615], Juan de Santa Cruz Pachacuti [1613*], Bernabé Cobo [1653*], entre otros.

\section{Palabras clave}

Derecho, aclla, mujer pública, acllahuasi, religión

\section{ABSTRACT}

This study presents the norms that regulated the life of the Chosen Ones (Sun virgins) and the prostitutes during the Inca times, according to the work written by Inca Garcilaso de la Vega. All references are from his Comentarios reales de los Incas 1609 (1st edition)-1616 (2nd edition)] published in Lima (1985) by the Peruvian National Library. The subjects explained here are contradicted, enlarged or complemented by the chronicles of Francisco de Xerez (1534), Juan de Betanzos [1551], Pedro Cieza de León [1553], Juan de Matienzo [1567], Pedro Pizarro [1571], José de Acosta [1590], Blas Valera 1588 (?)], Miguel Cabello de Balboa [1586], Martín de Murúa [1590], Antonio de Herrera (1615), Guamán Poma de Ayala [1615], Juan de Santa Cruz Pachacuti [1613], Bernabé Cobo [1653] among others.

\section{Keywords}

Law, aclla, acllahuasi, prostitute, religion

Doctora en Filología por la Universidad Complutense de Madrid. Tiene tres maestrías. Directora del Centro de Investigación de la Universidad Femenina del Sagrado Corazón. Docente ordinaria de la UNIFÉ. 


\section{DOS SECTORES: LAS ESCOGIDAS Y LAS PROSTITUTAS Y SU ESTATUTO EN EL DERECHO}

La mujer dentro de la sociedad incaica aparece con un régimen jurídico concreto, tal es el caso de las "escogidas" y las prostitutas.

\section{Las escogidas}

Garcilaso diferencia dos tipos de "escogidas"2: las "mujeres delSol"3 (1985 [16091. a -16162. a], p. 136) que vivían sólo en el Cuzco dedicadas a su servicio y a su templo ${ }^{4}$ y las escogidas ${ }^{5}$ para el inca que vivían en otros templos a lo largo del Tahuantinsuyo ${ }^{6}$. Aunque Murúa y Valera coinciden en que había escogidas ${ }^{7}$ del $\mathrm{Sol}^{8}$ en diversos templos ${ }^{9}$ en todo el imperio. ${ }^{10}$

De acuerdo a Garcilaso, las esposas del Sol pertenecían a la más rancia nobleza. Sin embargo, procedían de diferentes sectores sociales porque Valera dice que anualmente se convocaba a "cualquier virgen que quisiese de su voluntad ir a ser aclla $^{11}$ en el templo del" (1945 [1588?], p. 39); además, según Murúa "eran traídas de las cuatro provincias sujetas al Inga". ${ }^{12}$

2 Fernando de Montesinos dice que el iniciador de los acllahuasis fue el inca Capac Yupanqui, dice "á las doncellas que pasaban de los quince, hacía tomasen maridos; y cuando no querían, los mandaba depositar en un recogimiento, unas para el servicio del sol, y otras para que sirviesen a éstas, que después se convirtieron en uso profano [...]. Llámanse mamaconas (digo acllaconas) ó mujeres del servicio del sol” (1882 [1630*], p. 41).

3 Cobo señala que a las acllas las casaban con diferentes dioses en "ceremonias y solemnidad y de allí adelante eran llamadas y tenidas por mujeres suyas" (1956 [1653*], p. 332). Cobo es el único cronista, de entre los que se ha revisado, que presenta esta particularidad.

4 Valera señala que servían al Sol, pero también "a la luna y al lucero" (p. 40). Polo de Ondegardo da mayores precisiones, dice que se destinaba algunas acllas "al lucero que ellos llaman cuquilla que tenía casa y servicio solene en la ciudad del Cuzco, también tomaba para la Pachamama y para otras cosas de su religión y luego se apartaba otras para los sacrificios" (1917 [1571*], p. 83).

5 Francisco de Xerez menciona una casa de escogidas que vio en Cajas con acllas que trabajaban "una casa grande, fuerte y cercada de tapia, con sus puertas, en la cual estaban muchas mujeres hilando y tejiendo ropa para las huestes de Atabalipa, sin tener varones, más de los porteros que las guardaban" (1891 [1534], p. 54).

6 Valera señala que Pachacutec fue iniciador del ministerio de las acllas. Garcilaso dice que las vírgenes del Sol sólo estaban en el Cuzco y eran sólo nobles; en cambio, las mujeres del inca estaban en diversos acllahuasis en todo el imperio y eran las mujeres más hermosas de toda condición social.

7 Las escogidas recibían diversos apelativos: acllas, ñustas, mamaconas, intip chinan ('hembra del Sol'), punchao chinan ('hembra del Sol'). Valera las adscribe al mito solar propio de la cultura occidental porque señala que los dos últimos apelativos equivalen a "criadas del sol, siervas de la luz del día" (1945 [1588?], p. 38). Miguel Cabello Valboa dice que a las más ancianas que enseñaban y dirigían el acllahuasi las llamaban "Mama Aclla", a las más hermosas llamaban "Guayor Aclla" (< wayrur aqlla) y las que recién entraban de 12 a 15 años eran "Sayapayas".

8 Las acllas tenían diversas tareas, las mayores (mamacuna) cuidaban a las jóvenes. Según Pedro Pizarro ayudaban a cultivar "las sementeras del sol y del Ynga, y en hazer rropa delgada para los señores, digo / en hilar lana, porque el texello uarones lo hazían, y asimismo éstas se ocupaban en hazer chicha para los yndios que cultiuauan las tierras del sol y del Ynga, y para si pasauan guarniciones de xente de guerra por su tierra, darles de comer desta chicha" (1986 [1571*], pp. 94-95), lo que desdice la afirmación de que una de sus tareas era el tejido, pero al parecer sí confeccionaban ropa para el Inca y la coya y ropa finísima (compi) que ofrecían al Sol en sacrificio y un pan llamado çancu (era una comida ceremonial, hecha de sangre y harina), preparar una bebida llamada aca (aqha 'chicha'), entre otras actividades. Blas Valera señala que "tejían ropa finísima para el templo, para los dioses, para Vilashoma y para el rey y la reina y para sus padres y hermanos, si los tenían, o para sus tutores y curadores" (1945 [1588?], p. 43). Algunas sembraban, otras eran cantoras, porteras, provisoras que pedían lo que se necesitaba. También guardaban el fuego para los sacrificios nina villca. Todo se les proveía con abundancia porque eran mujeres del Sol y tenían a su servicio doncellas hijas de nobles de privilegio.

9 Valera se refiere a una cantidad apreciable de templos del sol "De manera que en todas las provincias donde había templos del sol, se ponían en cada uno doncellas de la misma nación, o de los pueblos sujetos a la tal provincia; empero en el templo del Cuzco, había doncellas de todas las naciones" (1945 [1588?], p. 39).

10 Eran gobernadas por la de mayor rango que era esposa del Sol, generalmente la hermana del inca, indicativo de que en los templos de las escogidas se mantenían las diferencias de clase que sólo se pudo mantener gracias a una disciplina rígida.

11 Murúa señala que las escogidas del inca debían ser hijas legítimas, sin mancha en el rostro y, en algunas casas de recogimiento, en todo el cuerpo, no debían ir forzadas porque las devolvían y castigaban al que las había llevado.

12 Polo de Ondegardo presenta detalles sobre el envío de las acllas al Cuzco, dice que cada año en la fiesta "del raymi en la ciudad del Cuzco, las llevaban a aquella ciudad, conforme a lo que a cada provincia vavia, [...] todas iban de trece y catorce años para arriba [...] de todas las provincias, que eran en grandissima cantidad, mediado el mes de Março" (1917 [1571*], p. 82) 
Las mujeres del Sol tenían más rango ${ }^{13}$ que las del inca ${ }^{14}$, porque estas últimas, según Garcilaso, eran "donzellas de todas suertes ${ }^{15}$ [...] escogidas por muy hermosas, porque eran para mujeres o concubinas del Inca y no del Sol" (1985 [1609 1. a -1616 2. a], p. 139). La diferencia estriba en la dignidad superior del Sol a quien el inca le debía su existencia, por lo cual, "no podía darlas a otro alguno que no fuesse de su sangre real y parentela" (1985 [1609 1. ${ }^{\mathrm{a}}-1616$ 2. ${ }^{\mathrm{a}}$, p. 138). En cambio, podía disponer de "sus mujeres", reservaba algunas para sí, para los curacas entregándoles acllas nobles para crear alianzas políticas, las daba a los jefes guerreros, y servidores ${ }^{16} \mathrm{o}$ se sacrificaban.

A pesar de que según Garcilaso las acllas no salían nunca del acllahuasi, Pedro Pizarrro ${ }^{17}$ dice que el inca ordenaba que saquen a "las más hermosas para llevárselas donde él estava" (1986 [1571*], p. 139), pero esas acllas al perder su virginidad, no podían volver a su acllahuasi, y se quedaban a servir en la casa real ${ }^{18}$. Además, Murúa manifiesta que al llegar a la edad de matrimonio, las "que no eran tan hermosas ni tan nobles, podían sus padres casar con quien quisieren" (1946 [1590?*], p. 419), pero con la autorización del inca. Éste debió ser el sistema, de lo contrario los acllahuasis hubieran colapsado con una población tan grande que era imposible sostener.

Garcilaso dice que cada año se recogía niñas o púberes, aunque no existe consenso sobre la edad ${ }^{19}$. Valera desmiente que las escogidas fuesen llevadas como tributo, dice que "No iba esto por tanda, como algunos interpretaron, ni menos por fuerza, como a Polo ${ }^{20}$ le pareció,

13 Martín de Murúa relata un episodio que revela el proceso de mitificación que se iba generando sobre el perfil social de las acllas dedicadas al Sol como seres superiores que habían superado necesidades biológicas. Narra que las del templo "en la sierra nevada que está junto a Yucay, llamada Savasiray [...] las cuales ninguna necesidad tenían de manjares para sus comidas, mas solamente vivían del olor de una cierta comida y fruta que tenían silvestre; y cuando iban de camino fuera de su casa y recogimiento, llevaban consigo para su provisión de aquella fruta y para sustentarse de aquel olor; y si acaso algún mal olor gustaban" (1946 [1590?*], pp. 262-263). Transcribo lo contenido en nota (1) de la p. 263 sobre "FRAY PEDRO SIMÓN. Noticias historiales de las conquistas de Tierra-firme en las Indias Occidentales. Noticia 1. a , cap. 2, tomo I, página 5. Bogotá, 1882.-El testimonio del P. Gregorio García va más lejos que el de Murúa: Alarga el don verdaderamente envidiable a todos los indios "de cierta parte del Perú, que está dentro de las montañas, a los cuales los proveyó la naturaleza de una virtud atractiva para que con ella chupen y atraigan la sustancia del manjar que ponen guisado junto a la boca". Origen de los indios del Nuevo Mundo, lib. II, cap. 3, pág. 61. Madrid, 1729.”.

14 Según Fernando Montesinos el iniciador de las escogidas para el inca fue Inca Roca que "Mandó hacer junto al templo una casa ó convento de doncellas para el servicio dél, —de donde queda la costumbre de servir ahora las muchachas á la iglesia_" (1882 [1630*], p. 110).

15 Garcilaso señala que en el acllahuasi del inca entraban "donzellas de todas las suertes, assí de las legítimas de la sangre real como de las que llamamos bastardas, mezcladas con sangre ajena. Entravan también, por gran favor y merced, hijas de los curacas, señores de vassallos; assimismo entravan hijas de gente común las que eran escogidas por muy hermosas" (1985 [1609 1. $.^{\mathrm{a}}-16162$ 2. $^{\mathrm{a}}$, p. 139).

16 Según Murúa, el inca entregaba a las acllas de la siguiente manera: las de la primera casa, que eran las más nobles y hermosas, a sus capitanes que se "señalaban" en sus servicio y le eran más próximos, las de la segunda casa casi no las entregaba porque eran para él, las de la tercera las entregaba a los "principales", las de la cuarta "a los comunes" en las de la quinta "a los indios pobres" y las de la sexta "a los indios viejos, feos y del jaez dellas".

17 Pedro Pizarro dice que a la más hermosa "la enbiauan al señor" (1986 [1571*], p. 95).

18 Garcilaso dice que las acllas tomadas por el inca no volvían al acllahuasi y "servían en la casa real como damas o criadas de la reina hasta que las juvilaban y davan licencia que se bolviessen a sus tierras, donde les davan casas y heredades y las servían con gran veneración [...] Las que alcançavan a ser concubinas del Rey se quedavan en la casa hasta muy viejas; entonces tenían libertad para irse a sus tierras, donde eran servidas como hemos dicho, o se quedavan en las casas hasta morir" (1985 [1609 1. a -1616 2.a], p. 140).

19 No existe consenso sobre la edad de las niñas que se recogían. Garcilaso dice que ingresaban menores de 8 años. Murúa señala que el quinto recogimiento se llamaba Vinachicuy "que se decían criadas, o causa que entraban muy pequeñuelas de cinco o seis años" (1946 [1590?*], p. 255). En cuarto recogimiento "habían de ser muchachas de nueve hasta quince años" (1946 [1590?*], p. 252), en el sexto "eran de quince años hasta diez y ocho" (1946 [1590?*], p. 258), pero no menciona la edad de las mujeres de los tres primeros recogimientos, pero debían ser menores de dieciocho años porque a esa edad se les destinaba a Sol; y a las escogidas del inca a ser su concubina o salían para casarse. En cambio Valera dice que las acllas del Sol se elegían entre púberes mayores de doce años. Miguel Cabello de Valboa dice que entraban de 12 a 14 años y de 15 a 25 años eran elegidas para el Sol o para el inca.

20 No sólo Polo de Ondegardo dice que las acllas eran tributo, también lo menciona Francisco de Xerez "demás del tributo que le dan de sus haciendas y granjerías, se lo dan de sus hijos." (1891 [1534], p. 54). 
sino muy a gusto de las vírgenes y de sus padres; y aún vino el negocio a tanta estima entre ellos, que rogaban los padres para que recibiesen a sus hijas, y aún había intercesores para que lo alcanzasen" (1945 [1588?], p. 39). Argumenta que si no se hubiera procedido de esa manera hubiera sido imposible que ese régimen se mantuviese porque ninguna cosa obligada dura para siempre. Coincide con Garcilaso que dice que "Los padres tenían por suma felicidad que les tomassen las hijas para mujeres del Rey, y ellas lo mismo" (1985 [1609 1. ${ }^{\mathrm{a}}-1616$ 2. ${ }^{\mathrm{a}}$, p. 139).

Aunque Garcilaso señala que todas las acllas del Sol y del inca se dedicaban al tejido, Murúa menciona que a las del inca se las separaba ${ }^{21}$ en seis casas de recogimiento "repartidas por los pueblos" (1946 [1590?*], p. 246) por su belleza, rango social, capacidad para el canto, ser extranjeras y se les delegaba actividades laborales propias, excepto a las más hermosas que no trabajaban ni servían a nadie.

Pese a que Garcilaso afirma que "las mujeres del Sol no havían de ser tan comunes que las viese nadie" (1985 [1609 1. $^{\mathrm{a}}-1616$ 2. ${ }^{a}$, p. 136), como esposas del Sol debían salir al templo o a los lugares donde se le ofrecían celebraciones ${ }^{22}$. Además, tenían ritos propios. Por ejemplo, según Cobo, sólo ellas podían sacar "en público" (1956 [1653*], p. 233) el ídolo de la Luna, llevar la chicha para los sacrificios y para dar de beber a los sacerdotes. También participaban en las fiestas religiosas, Cieza de León menciona que en la fiesta de la Capacocha estaban presentes "el mesmo rey, acompañado de sacerdotes y mamaconas que allí se habían juntado" (1967 [1553], p. 101); igualmente señala que en la fiesta de Hatun Raimi "mandaban salir a las vírgenes mamaconas arreadas ricamente y con mucha multitud de chicha quellas tenían hecha" (1967 [1553], p. 104) y la daban de beber a todos y participaban de la fiesta y los hombres empezaban a cantar acompañados de "muchos atabales de oro engastonados algunos de pedrería, los cuales les tañían sus mujeres, que juntamente con las mamaconas sagradas les ayudaban a cantar" (1967 [1553], pp. 104-105). Otra fiesta importante, según Valera, era la renovación anual de su obediencia a la que concurría mucha gente "por ver las vírgenes que todas a una mano eran en extremo hermosas" (1945 [1588?], p. 45); allí ellas repartían chicha y pan entre la gente. Además, frecuentemente salían, como dice Valera, a "visitar los templos y los santuarios que había en el pueblo, y a limpiarlos y aderezarlos" (1945 [1588?], p. 43); pero siempre iban acompañadas " $y$ traían una lanza en la mano y un arco con sus flechas" (1945 [1588?], p. 43).

Esto contradice la afirmación de Garcilaso cuando dice que "esta clausura era tan grande que aun el proprio Inca no quería gozar del privilegio que como Rey podía tener [...] Sola la Coya, que es la Reina, y sus hijas tenían licencia para de entrar en la casa y hablar con las encerradas, assí moças como viejas" (1985 [1609 1. a -1616 2. a], 136). Sin embargo, Bernabé Cobo manifiesta que a veces entraba el Inca de noche en su recinto y para purificar la transgresión, cualquiera de los subsiguientes días, cuando el Inca participaba en la plaza del

21 En la primera, estaban las hijas de los señores de más alto rango "escogidas y hermosas, sin que tuviesen falta o defecto en todo el cuerpo" (1985 [1609 1. a -1616 2. a], p. 246), nadie las podía ver, salvo el inca y alguna vez los señores de su consejo. No trabajaban y no servían a nadie. Las escogidas de la segunda casa no eran tan hermosas, pero eran de linaje, trabajaban y entraba sólo el inca, también lo autorizaba a grandes personajes. Las de la tercera casa eran pobres trabajaban igual que las de la segunda casa, salían para preparar la comida del inca y usaban un vestido especial, al que se enamoraba de ellas le sacaban los ojos. Las de la cuarta casa se las elegía por su buena voz, eran cantoras y tocaban tambores para el inca, además pastaban el ganado para los sacrificios. Eran del linaje del inca. Entraban a los ocho años y permanecían hasta los quince, pero las escogían desde los seis años. La quinta casa entraban de cinco años eran de todas las clases sociales y no debían tener fealdad en el cuerpo, tejían y se cocinaban para el inca y estaban siempre encerradas. En la sexta casa estaban las de quince a dieciocho años eran escogidas y no tenían ningún defecto o mancha, se dedicaban a la labranza y el inca las visitaba a cada una en su aposento.

22 Antonio de la Calancha menciona que las mamaconas del Sol salían en el mes de setiembre en la fiesta al Sol, Citua, en la cual "quemávanse cien carneros blancos lanudos al Sol, i se azía la gran fiesta llamada Citúa, i se juntavan todos antes que saliese la Luna [...] i bevían quatro días continuos, sacavan las Mamaçonas del Sol, que eran sus Virgines, i davan bollos a los forasteros rociados con sangre de sus sacrificios" (1976 [1639], 51 t. III). 
Sol del sacrificio cotidiano, por detrás de él se le acercaba uno de los guardas del templo, se sentaba a su lado "le trababa de la manta y le decía muy quedo: "Inca, esta noche entraste en la casa del sol, y tuviste que ver con una de sus mujeres." Y el Inca así quedo respondía: "Pequé". Y con esto se volvía la guarda seguro de no haber faltado a su debida custodia y vigilancia" (1956 [1653*], p. 232). Esto era posible por la vigilancia estrecha en el templo de las acllas. Según Garcilaso, una primera puerta la resguardaban veinte porteros, pero no podían traspasar la segunda puerta, aunque les ordenasen desde adentro so pena de muerte.

Según Garcilaso la posición de las escogidas del Sol era privilegiada porque se las respetaba. Nadie podía agredirlas verbalmente o levantarles la mano. Valera menciona que cuando "pasaban por la calle acompañadas de sus criados y guardas, [y] se acogía a ellas un delincuente, no le podía prender la justicia" (1945 [1588?], p. 47), situación semejante a la inmunidad que ganaba un delincuente en el siglo XVII cuando ingresaba en una iglesia al ser perseguido por la justicia.

Si una de esas escogidas faltaba a la virginidad, al decir de Garcilaso, se la enterraba viva y al cómplice se le mandaba ahorcar; además a su "mujer y hijos y criados, y también sus parientes y todos los vezinos y moradores de su pueblo $\mathrm{y}$ todos sus ganados, sin quedar mamante ni piante, como dizen" (1985 [1609 1. ${ }^{\mathrm{a}}$-1616 2. ${ }^{a}$, p. 138), destruían las casas y el lugar lo llenaban de piedras para que nunca vuelva a ser habitado. Esa ley se cumplía sin perdón. Guamán Poma de Ayala señala además que por simple atisbo o sospecha contra su castidad se las castigaba, por ejemplo, por "hablar y conversar o enviar otro que le hablen por ellos con color de pecar con los hombres" (1993 [1615*], p. 235); en ese caso eran condenadas a morir colgadas de los cabellos. En los otros acllahuasis, si un hombre intentaba violar ese recinto era quemado vivo con la aclla, si tenía la culpa, y se procedía de la misma manera que con las del Cuzco y se asolaba la tierra. Bernabé Cobo menciona otro castigo, dice que al hombre que escalaba la casa de las escogidas lo mataban colgándolo de los pies y si una aclla tenía culpa le daban el mismo castigo y se aplicaban dentro de ese recinto. Miguel Cabello de Valboa dice que "los ataban bibos juntos, y muy liados los colgauan" (1953 [1586*], p. 349).

Aunque Garcilaso señala que nunca hubo violación del acllahuasi, la variedad de pena de muerte que se aplicaba sugiere transgresiones, como también el hecho de que al ser las acllas las mujeres más hermosas ${ }^{23} \mathrm{del}$ imperio podían despertar aficiones ${ }^{24}$; además, obran la diferencia de caracteres o inclinaciones propias de la personalidad de cada una. Cieza de León relata que en tiempo del Inca Viracocha durante la rebelión de Capac cuatro acllas "usaban feamente de sus cuerpos con ciertos porteros de los que [las] guardaban; $y$, siendo sentidas, fueron presas y lo mesmo a los adulteradores, y el sacerdote mayor mandó que fuesen ajusticiados ellas y ellos" (1967 [1553], p. 137). Este es un caso aislado, pero Pedro Pizarro generaliza como un comportamiento usual en el incanato "dezían ellas que eran mujeres del sol, y finxían guardauan virginidad y ser castas, y mentían, porque también se emboluían con los criados y guardadores del sol, que heran muchos" (1986 [1571*], p. 92). Francisco de Jerez dice que Atahualpa en Cajas mandó matar a un violador del acllahuasi y a los guardas por ese delito ${ }^{25}$.

23 La hermosura de las acllas sobresalía porque una de sus actividades era cuidar su belleza. Martín de Murúa refiere que "tenían gran cuidado de su hermosura, y por esto hacían cuanto podían para guardar la cara" (1946 [1590?*], p. 263).

24 Luis Baudin refiriéndose a las mujeres habla de "El triste papel de la mujer" del pueblo que ocupaba una posición inferior y se hallaba abrumada de obligaciones por las cuales "no tenía casi tiempo para ocuparse de sí misma" (1962, p. 251), a diferencia de las acllas que tenían un tiempo para dedicarlo a su persona y arreglarse, posiblemente pintarse las mejillas con achiote (wantur o mantur en quechua y aimara), limpiarse los dientes con hoja picante de cabuya o aplicarse hierbas cocidas en las encías para que se desprenda la piel quemada y aparezca con un atractivo color rojo; además se lavaban y cuidaban su atuendo que era de lana fina.

25 Francisco de Xerez dice que "á la entrada del pueblo habia ciertos indios ahorcados de los piés; y supo deste principal que Atabalipa los mandó matar porque uno dellos entró en la casa de las mujeres á dormir con una; al cual, y a todos los porteros que consintieron, ahorcó" (1891 [1534], p. 54). 


\section{Las prostitutas}

Una posición opuesta a las vírgenes del sol tenían las prostitutas, aunque esa condición no era voluntaria sino impuesta. Betanzos señala que para evitar que los solteros asedien a las casadas o mamaconas ${ }^{26}$ el Inga Yupangue ordenó que algunas prisioneras de guerra sean mujeres públicas y vivan en una casa en las afueras de los pueblos. En cambio, Garcilaso señala que cada prostituta "Vivía en los campos, en unas malas choças cada una de por sí y no juntas" (1985 [1609 1. a -16162.a], p. $150)$ y tenía la orden de no entrar nunca en los pueblos ni comunicarse con otras mujeres, lo cual revela la visión infamante que generaban. A tal punto, que si una mujer hablaba con ellas le cortaban públicamente el cabello ${ }^{27}$, perdía su honra y era repudiada por su marido. Betanzos afirma que si a un hombre casado se le encontraba con una de esas mujeres se lo llevaba a la plaza para que "atado de pies y manos el cual fuese vituperado de los parientes de la mujer y que los tales parientes le quitasen a la tal mujer [su esposa] por cierto tiempo" (1987 [1551*], p. 107).

El estatuto de las mujeres públicas era humillante: esto determinó que los hombres se arrogasen el derecho de tratarlas, como dice Garcilaso, "con grandissimo menosprecio" (1985 [1609 1. a -1616 2.a], p. 150), actitud opuesta a la dignidad que adquirían las acllas o vírgenes del Sol, que eran respetadas y se las veía con reverencia. Más aún porque se valoraba la virginidad, ya que cada año se recogía en todo el imperio a las niñas más agraciadas para destinarlas a los sacrificios o enviarlas a los muchos templos de las escogidas en todo el imperio.

En ese referente, se evidencia un nivel absoluto de repudio a la prostitución. Un indicador se manifiesta en las penas que se aplicaban a las mujeres propias si se depravaban. Guaman Poma de Ayala señala "que la mujer corrompida o que consentía que la corrompiesen, o fuese puta, que fuese colgada de los cabellos o de las manos en una peña viva en Antacaca; y que le dejen allí morir" (1993 [1615*], pp. 141-142); y según Antonio de Herrera, los gobernadores y visitas que enviaba el inca "castigaban a las mujeres solteras que hallaban ser deshonestas" (1952 [1615], p. 285) y a las públicas con pena de muerte; además, si una mujer pública se casaba sin licencia del Inca su matrimonio no era válido. En esas condiciones de ausencia total de reivindicación, era comprensible que las prostitutas perdiesen toda dignidad humana, al punto que las despersonalizaban y no interesaban sino como medio. Perdían su apelativo porque nadie las llamaba por su nombre propio sino por el genérico despectivo pampairuna ${ }^{28}$, en castellano ramera. Garcilaso explica que este apelativo

significa la morada y el oficio, porque es compuesto de pampa que es plaça o campo llano (que ambas significaciones tiene), y de runa, que en singular quiere dezir persona, hombre o mujer, y en plural quiere dezir gente. Juntas ambas dicciones, si las toman en significación

\footnotetext{
26 Las mamaconas eran las acllas mayores y las mujeres que habían perdido a sus hijos y criaban a los expósitos y a los hijos de las prostitutas. El concepto de mamaconas al parecer tiene varias acepciones. Pedro Pizarro dice que a las indias hermosas que se entregaban al "señor" (Inca) "Estas se llamauan mamaconas" (1986 [1571*], p. 95). Blas Valera señala que mamacona era cualquiera de las escogidas, sin diferencia de edad "si eran doncellas, pertenecía a las mamaconas, matronas y superioras de monasterio." (1945 [1588?], p. 40), pero coincide con Pizarro en señalar que las superioras que recibían ese apelativo "estaban a la obediencia de sus mamaconas (que así decían las superioras)" (1986 [1571*], p. 42).

27 Véase en nota 10 el significado del corte de pelo.

28 Waldemar Espinoza afirma que además del apelativo pampairuna, a las prostitutas las llamaban "mitahuarmis: mujeres de turno". Y hoy mismo tienen otros muchos nombres en quechua: pacha raka, panpa warmi, $k$ 'ita warmi, tuqlla warmi, y la popular ch'aran qara. He aquí el Campo Semántico que en Calvo Pérez, Julio (2009): Nuevo diccionario español-quechua, quechua-español. Lima, USMP, 2009: "PROSTITUTA (O): (salida), aricha; (cerda, guarra), china khuchi; (chola), chula; (pelleja), ch'allqi; (mojada, suripanta, zorra), ch'aran qara; (culo śfácilș), kachi siki; (buscona, chivatera I), kalli k’anchay; (fulana, furcia; pasada), mankha; (mujer lujuriosa), ñuki warmi; (puta śelegidaș), palla; (buscona), pata warmi; (golfa), paytu; (cualquiera, mujer śfácilș), phasil siki; (seca), qacha (qacha warmi); (meretriz), q'ita (k'ita); (mugrienta), qhanra; (patosa), ranpha; (cortesana, hetaira), salla; «+vulg.» (chusquisa $\uparrow)$, siqsi siki; (pelandusca), tuqlla warmi; (ninfómana), wanarpu; (pululante), wakwaña".
} 
del campo, pampairuna quiere dezir gente que vive en el campo, esto es por su mal oficio; y si las toman en su significación de plaça, dando a entender que, como la plaça es pública y está dispuesta para recebir a cuantos quieren ir a ella ${ }^{29}$ (1985 1609 1. ${ }^{a}-1616$ 2. ${ }^{a}$, p. 150).

Dentro de la vida cotidiana en el imperio de los incas, la posición de la mujer y del hombre era diferenciada: se premiaba a la mujer que tuviese un hijo varón. Los hombres, incluso pobres, podían tener por lo menos dos mujeres; pero las viudas, según Garcilaso, no podían volver a casarse y debían vivir en "castidad y limpieza" (1985 [1609 1. a -1616 2. a], p. 142), de lo contrario la "quemaran viva o la echavan en el lago de los leones" (1985 [1609 1. ${ }^{\mathrm{a}}-1616$ 2. ${ }^{\mathrm{a}}$ ], p. 142). Las mujeres no podían tener contacto con las armas en tiempo de guerra y los hombres no podían tocar ninguna cosa de su uso. Además, dentro del campo del derecho se tenía un concepto devaluado de la calidad personal de la mujer porque su palabra no se consideraba y carecía de valor: "Iten mandamos que ninguna mujer no valiese por testigo por ser embustera, y mentirosa y pusilánime, pici songo" (1993 [1615*], p. 140 Guamán Poma de Ayala).

Los hijos de las prostitutas eran llamados churi que según Betanzos significa 'hijo del común' porque no se sabía quién era el padre. Para criarlos, apenas nacían, los llevaban a una casa donde las mamaconas, mujeres de diversas partes del imperio que habían perdido a sus hijos los criaban. Guamán Poma de Ayala señala que para ayudar a criar a esos niños "Iten mandamos que las dichas amas de huérfanos, uaccha rurocha nunochic, sean reservadas de todo, y le den otra niña grande para que le ayude a criar, éstas se llaman mamaconas" (1993 [1615*], p. 145). Esa casa se puede considerar un orfanato donde se recogía a niños expósitos, sean hijos de mujeres nobles o del pueblo, donde, al igual que en la cultura occidental, se evitaba la vergüenza de la mujer y se salvaguardaba su honra ${ }^{30}$. Para contribuir a mantener el anonimato, se depositaba mucha paja debajo de los puentes ${ }^{31}$ y en secreto por la noche se dejaba a los niños recién nacidos. Si los guardas preguntaban a dónde se iba, porque era prohibido caminar fuera de casa de noche, si le respondían que se iba a dejar un niño nadie preguntaba más. Por esa razón cada mañana se miraba debajo del puente si se había dejado algún niño.

Los niños eran criados por las mamaconas y cuando crecían eran enviados a trabajar en los sembríos de coca $^{32}$ que demandaba mano de obra porque, según Garcilaso, se recogían "tres vezes al año" (1985 [1609 1. ${ }^{\mathrm{a}}-1616$ 2. $\left.{ }^{\mathrm{a}}\right]$, p. 349). Ese era un trabajo duro e insano33; tanto es así que Bernabé Cobo señala que

29 Para Garcilaso panpa es también por sí mismo 'prostituta' y como adjetivo: 'de abajo, corriente, vulgar; sin valor añadido'. Según el Nuevo diccionario español-quechua, quechua-español de Julio Calvo Pérez es como el panpa misayuq entre los sacerdotes etc.; es decir, 'de baja estofa'. Como sustantivo que, al parecer, ya era real en aquella época, como metáfora.

30 Antonio de Herrera manifiesta que las mujeres solteras tenían "por cosa muy vergonzosa y deshonesta parir o tener preñado, antes de ser casadas, y si acaecía alguna flaqueza de éstas en alguna, procuraba matar el tal preñado" (1952 [1615], p. 287).

31 Antonio de Herrera ofrece algunas precisiones más, dice que como las madres solteras abandonaban a sus hijos que morían pisados por el ganado o despedazados por los perros, para remediarlo "el Inca mandó hacer una concavidad en una pared tan alta, que perros no pudiesen alcanzar a ella, y mandó pregonar con gran diligencia que cuando lo tal acaeciese a alguna mujer, pusiese la criatura en aquel lugar, con apercibimiento que si alguna hiciese lo contrario, que moriría por ello [...] y señaló personas que todas las mañanas fuesen a visitar aquel lugar, y si hallasen alguna criatura la llevasen a una casa, que él mandó hacer, donde se criasen a su costa" (1952 [1615], p. 287).

32 Aunque Garcilaso menciona que "A estas bolsas llaman chuspe: servía solamente de traer la yerba llamada cuca, que los indios comen, la cual entonces no era tan común como ahora, porque no la comían sino el Inca y sus parientes y algunos curacas a quien el Rey, por muchos favores y merced, embiava algunos cestos della por año" (1985 [1609 1. a -1616 2. $\left.{ }^{a}\right]$, p. 137). Era una planta sembrada con profusión, lo que es señal clara de un empleo común.

33 El cronista Juan de Matienzo al referirse al trabajo con la coca menciona el rumor que existía alrededor de 1567, año en el que envía su crónica a España para que sea revisada por el Consejo de Indias: "dicen, también, donde se cría esta coca es caliente y húmida, y muy enferma para los indios de la sierra, y que comunmente mueren muchos indios que andan en el beneficio de ella, y otros cobran una enfermedad que llaman de los Andes, que se comen las narices como mal de San Lázaro, aunque no es contaxioso, ni acaba al hombre presto, antes viven mucho con aquella enfermedad" (1882 [1630*], p. 162). 
uno de los castigos era ser desterrado "a la provincia de los Andes, tierra enferma, [...] en las chácaras de coca ${ }^{34}$ del Inca" (1956 [1653*], p. 126), donde una de las enfermedades más temidas era la uta.

A partir de los puntos tratados se puede señalar que Garcilaso presenta una visión de la cultura del imperio mediatizada por una mirada personal que avala con sus recuerdos y sus lecturas, lejos del Perú en un tiempo en el que los medios de comunicación eran difíciles y precarios. Por ende, al leerlo es importante contrastar sus ideas con lo escrito por otros cronistas para enriquecer la visión de los temas que presenta en su riqueza y diversidad.

34 En las informaciones que mandó hacer el virrey Francisco de Toledo se menciona una leyenda sobre el origen de la coca que está relacionada con una mujer liviana "Y cerca del origen que tuvo, dicen todos que no lo saben, excepto seis testigos que dicen que entre los naturales se trataba que la dicha coca, antes que estuviese como está, en árboles, era mujer muy hermosa, y que por ser mala de su cuerpo la mataron y la partieron por medio, y della había nacido un árbol, el cual llamaron Mama Coca ó Coca Mama, y que desde allí la comenzaron a comer" (1981 [1572*], p. 198) 


\section{REFERENCIAS}

* Fecha de redacción

Acosta, José de (1954 [1590]) Historia natural y moral de las Indias en Obras del P. José de Acosta, Madrid, Biblioteca de Autores Españoles desde la Formación del Lenguaje hasta Nuestros Días.

Anónimo (1981 [1572*]) Informaciones acerca del señorío y gobierno de los Ingas hecha por mandado de Don Francisco de Toledo Virey del Perú 1570-1572. Madrid, Establecimiento tipográfico de Juan Cayetano García, pp. 177-259.

Baudin, Luis (1962) La vida cotidiana en el tiempo de los últimos incas. Buenos Aires, Librería Hachette S. A.

Betanzos, Juan de (1987 [1551*]) Suma y narración de los incas. Madrid, Atlas.

Calvo Pérez, Julio (2009) Nuevo diccionario español-quechua, quechua-español. Lima, Universidad San Martín de Porres.

Cabello de Balboa, Miguel (1953 [1586*]) Miscelánea Antártica, una historia del Perú antiguo. Lima, Universidad Nacional Mayor de San Marcos Facultad de Letras Ediciones del Instituto de Etnología.

Calancha, Antonio de la (1976 [1639]) Crónicas del Perú. Lima, Ignacio Prado Pastor, 1976. t. I - III.

Cieza de León, Pedro de (1967 [1553]) Del señorío de los Incas (1553). Lima, Instituto de Estudios Peruanos, 1967.

Cobo, Bernabé S. J. (1956 [1653*]) Historia del Nuevo Mundo. En Obras de Bernabé Cobo de la Compañía de Jesús (1653 - 1890). Madrid, Biblioteca de Autores Españoles desde la Formación de la Lengua hasta Nuestros Días (continuación).

Espinoza Soriano, Waldemar (1990) Los Incas. Economía, sociedad y estado en la era del Tahuantinsuyo. Lima, Amaru Editores.

Estete, Miguel de (s/f [1535]) Noticia del Perú en Biblioteca Peruana (Primera serie). Lima, Editores Técnicos Asociados S. A., t. I

Garcilaso Inca de la Vega (1985 [1609 1. a -1616 2. a]) Comentarios reales de los Incas (1609 1. a

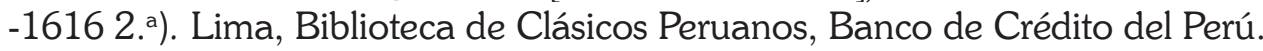

Guamán Poma de Ayala (1993 [1615*]) Nueva coronica y buen gobierno. Lima, Fondo de Cultura Económica.

Herrera, Antonio de (1952 [1615]) Historia general de los castellanos en las islas de Tierrafirme del mar océano. Madrid, Imprenta Editorial Maestre, t. X.

Kauffmann Doig, Federico (1963) Los incas y el Tahuantinsuyo. Lima, Peruanística, Sociedad Académica de Estudios Americanos. 
Levillier, Roberto (1956) Los Incas, Sevilla, Escuela de Estudios Hispano-Americanos de Sevilla.

Matienzo, Juan de (1967 [1567*]) Gobierno del Perú. Lima, Institut Français D’Études Andines.

Montesinos, Fernando (1882 [1630*]) Memorias antiguas historiales y políticas del Perú (1630). Madrid, Imprenta de Miguel Ginesta, 1882. pp. i - xxxii / 1-176.

Murúa, Martín de, O. M. (1946 [1590?*]) Historia del origen y genealogía real de los Reyes Inças del Perú. Madrid, C. Bermejo, Impresor.

Pease, Franklin (1991) Los últimos incas del Cuzco. Madrid, Quinto Centenario, Alianza Editorial.

Pizarro, Pedro (1986 [1571*]) Relación del descubrimiento y conquista de los reinos del Perú. Lima, Pontificia Universidad Católica del Perú.

Polo de Ondegardo, Juan(1917 [1571*]) Informaciones acerca de la religión y gobierno de los incas, segunda parte, seguida de estado y economías de los naturales del Perú que se dicen indios y medios simplísimos de corregir. Lima, Imprenta Librería Sanmarti y Ca.

Rostoworoski de Diez Canseco, María (1988) Historia del Tahuantinsuyo. Lima, Instituto de Estudios Peruanos.

Santa Cruz Pachacuti, Juan de (1995 [1613*]) Relación de antigüedades de este reino del Perú. México, Fondo de Cultura Económica.

Santillán, Fernando de (1950 [1563*]) Relación del origen, descendencia, política y gobierno de los incas en Tres relaciones de antigüedades peruanas, Asunción Paraguay, Editorial Guarania, pp. 33-131.

Valcárcel, Luis E. (1959) Etnohistoria del Perú antiguo, Historia del Perú (Incas). Lima, Universidad Nacional Mayor de San Marcos - Patronato del Libro Universitario

Valcácel, Luis E. (1984) Historia del Perú antiguo a través de la fuente escrita. Lima, Librería Editorial Juan Mejía Baca.

Valera, Blas, S. J. (1945 [1588?]) Las costumbres antiguas del Perú y "La historia de los Incas". Lima, Editorial de Domingo Miranda.

Ward, Stavig (1996) Amor y violencia sexual: valores indígenas en la sociedad colonial. Lima, Instituto de Estudios Peruanos: University of South Florida.

Xerez, Francisco de (1891 [1534]) Verdadera relación de la conquista del Perú. Madrid, Establecimiento tipográfico de Juan Cayetano García.

Fecha de recepción: 30 de enero 2015

Fecha de aceptación: 24 de febrero 2015 